\title{
Evaluasi Pemeliharaan Taman di Areal Jogging Track dan Playground, Pusat Pemerintahan Kabupaten Badung
}

\author{
I Wayan Agus Rene Sanjaya ${ }^{1}$, Cokorda Gede Alit Semarajaya ${ }^{1 *}$, I Nyoman Gede Astawa²
}

1. Prodi Arsitektur Lanskap, Fakultas Pertanian, Universitas Udayana, Jl. P.B. Sudirman, Denpasar, Indonesia

2. Prodi Agroekoteknologi, Fakultas Pertanian, Universitas Udayana, Jl. P.B. Sudirman, Denpasar, Indonesia

*E-mail: coksemarajaya@unud.ac.id

\begin{abstract}
Evaluation of Garden in the Jogging Track and Playground area, Badung Regency Government Center. The use of plants in the jogging track and playground area at Puspem Badung is currently disrupting visitor activities because their growth has damaged pavements and facilities. Therefore, the implementation of garden maintenance is very important to be able to maintain the comfort of the visitors and the beauty of the garden. This study aims to evaluate the maintenance of the garden in the jogging track and playground area at Puspem Badung. The research method used is a survey method. The data collected in this study are primary data and secondary data. The data collection method is done by using observation, interview, questionnaire and literature study. Based on the research results, the implementation of maintenance is carried out independently by implementing an unit and special maintenance system. In the implementation of watering, pruning, silting and weeding activities, the performance of the workers exceeds the ideal working capacity standard except for sweeping and fertilizing activities. The perception of visitors to the physical condition of the garden is considered good, seen from the indicators of assessment including garden's cleanliness, pedestrian's cleanliness, cleanliness of benches, cleanliness of planter boxes, garden safety and the beauty of the garden. Suggestions in this research are that it is necessary to have a written standard operational procedures for garden maintenance and to propose tree pruning activities at least once every three months.
\end{abstract}

Keywords: garden evaluation, garden maintenance, maintenance system, Puspem Badung

\section{Pendahuluan}

Taman yang terdapat pada kawasan perkantoran dapat membangun suasana keindahan dan kenyamanan di lingkungan kerja bagi pegawai kantor dan masyarakat yang berkunjung untuk menggunakan fasilitas umum. Peletakan tanaman yang sesuai dengan konsep desain akan menghasilkan nilai estetika dari taman tersebut. Nilai estetika dari suatu taman tentu memerlukan pemeliharaan taman yang intensif. Pemeliharaan taman dimaksud untuk menjaga dan merawat areal taman dengan fasilitas yang ada di dalamnya agar kondisinya tetap baik dan sedapat mungkin mempertahankan keadaan yang sesuai dengan desain semula (Strenloff dan Warren, 1984).

Pusat Pemerintahan Kabupaten Badung adalah kawasan perkantoran yang terdapat fasilitas umum dan dapat digunakan masyarakat sekitar untuk berolahraga jogging serta sarana bermain bagi anak-anak. Penggunaan berbagai macam tanaman di areal jogging track dan playground Puspem Badung awalnya memiliki kondisi yang baik. Saat ini terdapat tanaman dengan jenis pohon seperti bunga kupu-kupu (Bauhinia blakeana), kerai payung (Filicium decipiens), kamboja (Plumeria sp.), trembesi (Samanea saman) dan buah buni (Antidesma bunius L.) yang pertumbuhannya sudah merusak perkerasan dan fasilitas bermain sehingga mengganggu aktivitas pengujung. Selain permasalahan tersebut, pihak pengelola taman sangat intensif dalam pelaksanaan pemeliharaan sehingga sangat menarik untuk mengetahui upaya yang telah dilakukan. Taman di areal jogging track dan playground Puspem Badung juga didukung dengan adanya elemen hardscape seperti pedestrian, kolam, planter box, bangku dan lampu taman. Oleh sebab itu, pelaksanaan pemeliharaan taman sangat penting perannya untuk dapat menjaga kenyamanan pengunjung dan keindahan pada taman. Penelitian ini bertujuan untuk mengevaluasi pemeliharaan taman di areal jogging track dan playground kawasan Puspem Badung, hasil dari penelitian ini diharapkan menjadi rekomendasi pemeliharaan taman yang efektif dan efisien sehingga dapat diterapkan oleh pengelola taman. 


\section{Metode Penelitian}

\subsection{Lokasi dan Waktu Penelitian}

Penelitian ini dilakukan di areal jogging track dan playground Kawasan Puspem Badung (Gambar 1). Penelitian ini dilaksanakan selama lima bulan pada bulan Januari 2020 hingga Mei 2020.

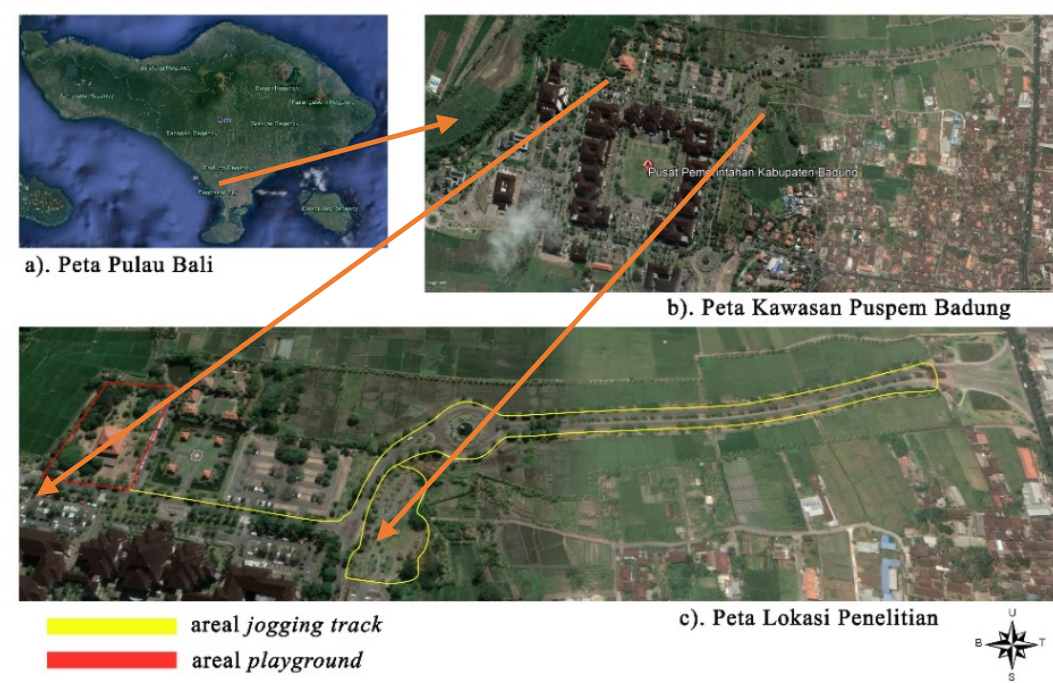

Gambar 1. Lokasi Penelitian

\subsection{Alat dan Bahan}

Alat dan bahan yang digunakan dalam penelitian ini adalah meteran, alat tulis kantor, kamera, laptop dengan aplikasi software Microsoft Office 2013, Google Earth, Adobe Photoshop CS6 dan lembar pertanyaan wawancara dan kuesioner untuk mengumpulkan data

\subsection{Pengumpulan Data}

Jenis data yang dikumpulkan pada penelitian ini yaitu data primer dan data sekunder. Data primer diperoleh melalui observasi, wawancara dan kuesioner. Observasi berupa data kondisi biofisik dan pemeliharaan taman. Wawancara ditujukan kepada Kepala Sub. Bagian Perawatan Puspem Badung, staf divisi pemeliharaan taman dan pengawas lapangan. Kuesioner ditujukan kepada 30 responden yang berusia minimal 17 tahun. Penyebaran kuesioner diberikan kepada pengunjung yang sedang beristirahat dan telah melewati areal jogging track dan playground Puspem Badung. Kuesioner ini dibagikan setiap hari sabtu dan minggu dari pukul 07.00-10.00 dan 16.00-18.00 dengan teknik pengambilan sampel secara acak. Sedangkan data sekunder merupakan studi pustaka yang bersumber dari buku, jurnal dan makalah ilmiah.

\subsection{Analisis dan Sintesis}

Data penyebaran kuesioner akan ditabulasi menggunakan analisis pembobotan skala Likert untuk memperoleh presentase (\%) dan dikonversikan kedalan diagram yang diuraikan secara deskriptif. Menurut Sugiyono (2017), yang dimaksud dengan skala Likert adalah skala yang digunakan untuk mengukur sikap, pendapat dan persepsi seseorang atau sekelompok orang yang berfokus pada objek atau fenomena sosial.

Analisis penghitungan kapasitas kerja pemeliharaan taman yang digunakan berdasarkan standar kapasitas kerja ideal Arifin dan Arifin (2005), dalam penelitian ini dapat dilihat pada Tabel 1.

Tabel 1. Kapasitas Kerja Operator Pemeliharaan Taman

\begin{tabular}{cll}
\hline No & \multicolumn{1}{c}{ Jenis Pemeliharaan Taman } & \multicolumn{1}{c}{ Kapasitas Kerja } \\
\hline 1. & Pembersihan/penyapuan & $800 \mathrm{~m}^{2} / \mathrm{jam} /$ orang \\
2. & Penyiraman rumput dan tanaman penutup tanah dengan selang plastik & $150 \mathrm{~m}^{2} / \mathrm{jam} /$ orang \\
3. & Pemangkasan rumput dengan mesin dorong rover & $500 \mathrm{~m}^{2} / \mathrm{jam} /$ orang \\
4. & Pemangkasan rumput dengan mesin gendong & $250 \mathrm{~m}^{2} / \mathrm{jam} /$ orang \\
5. & Penyiangan dan penggemburan tanaman semak dan penutup tanah & $40 \mathrm{~m}^{2} / \mathrm{jam} / \mathrm{orang}$ \\
6. & Pemupukan pada tanaman semak dan penutup tanah & $100 \mathrm{~m}^{2} / \mathrm{jam} / \mathrm{orang}$ \\
\hline
\end{tabular}

Sumber: Arifin dan Arifin (2005) 
Rumus dalam penghitungan kapasitas kerja adalah sebagai berikut:

$$
\text { Kapasitas Kerja }(\text { KK })=\frac{\text { Luas Lahan }}{\text { Waktu (1 Jam) } x \text { Jumlah Pekerja (1 Orang) }}
$$

Setelah dilakukan analisis data selanjutnya adalah sintesis yang merupakan tahapan pemecahan masalah dari objek penelitian yang berdasarkan tujuan penelitian. Hasil dari sintesis ini dapat menjadi rekomendasi pemeliharaan taman yang efektif dan efisien di areal jogging track dan playground Puspem Badung.

\subsection{Batasan Penelitian}

Lokasi penelitian dibatasi pada areal jogging track dan playground di kawasan Puspem Badung. Batasan ini dilakukan karena pengunjung yang datang lebih banyak melakukan aktivitas dan kegiatan pada areal tersebut. Persepsi terhadap kepuasan pengujung sangat dibutuhkan sebagai salah satu unsur penikmat dalam pemeliharaan taman, sehingga terdapat kesamaan persepsi dalam pengembangannya. Penelitian ini dibatasi pada tahap evaluasi terhadap pelaksanaan pemeliharaan taman.

\section{Hasil dan Pembahasan \\ 3.1 Gambaran Umum}

Pusat Pemerintahan Kabupaten Badung beralamat di Jalan Raya Sempidi No.43, Kecamatan Mengwi, Kabupaten Badung, Provinsi Bali. Puspem Badung memiliki luas keseluruhan adalah 46 hektar dengan persentase $60 \%$ area ruang terbuka dan $40 \%$ area bangunan (Wawancara, 2020). Kawasan Puspem Badung ramai dikunjungi oleh masyarakat sekitar, pada hari libur kerja atau hari sabtu dan minggu. Masyarakat berkunjung untuk melakukan aktivitas berolahraga dan berekreasi di areal taman jogging track dan playground.

Jalur lintasan jogging memiliki luas sepanjang 1 kilometer dan lebar 2 meter dari pintu masuk Puspem Badung. Kemudian terdapat tempat untuk berkumpul dan beristirahat bagi pengunjung yang dinamakan dengan taman jepun dunia karena dihiasi berbagai jenis tanaman kamboja atau jepun yang mewakili. Taman jepun dunia memiliki luas taman keseluruhan yaitu $5.500 \mathrm{~m}^{2}$. Setelah diamati, pada jalur lintasan jogging terdapat delapan titik paving yang rusak diakibatkan oleh pertumbuhan tanaman sehingga mengganggu aktivitas pengujung (Gambar 2a). Sementara pada areal playground memiliki luas taman keseluruhan yaitu $10.220 \mathrm{~m}^{2}$ dan banyak ditumbuhi tanaman perindang yang berfungsi sebagai tempat berteduh para pengunjung dan anak-anak yang sedang bermain, namun ranting-ranting tanaman perindang tersebut banyak berjatuhan sehingga dapat membahayakan keselamatan pengunjung (Gambar 2b).
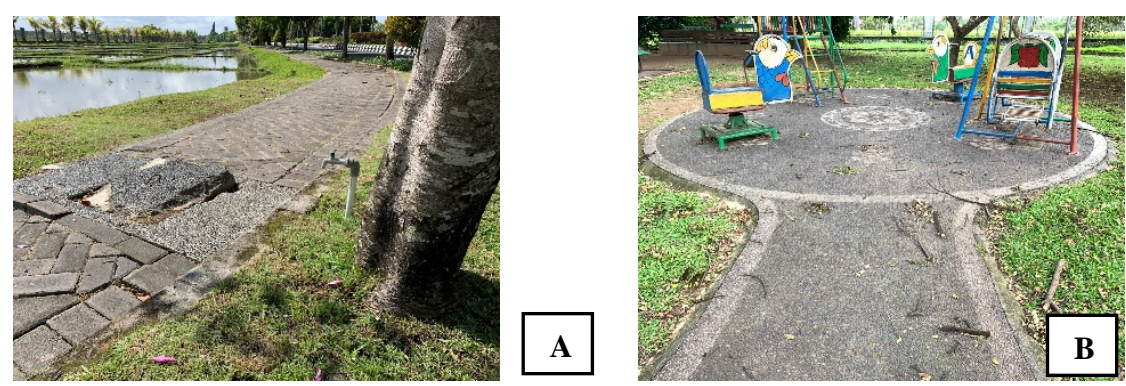

Gambar 2. (a) Kondisi Paving dan (b) Ranting Tanaman Berjatuhan

\subsection{Kondisi Fisik Taman}

Kondisi fisik taman di areal jogging track dan playground Puspem Badung terlihat indah dan bersih, dengan perpaduan elemen softscape dan hardscape.

a. Elemen softscape

Kondisi elemen softscape di areal taman jogging track dan playground Puspem Badung sudah tertata rapi dan indah, terdapat berbagai jenis tanaman yang memiliki fungsi dan peranannya masing-masing. Areal jogging track dihiasi dengan tanaman kamboja (Plumeria Sp.), bunga kupu-kupu (Bauhinia blakeana) 
dan kerai payung (Filicium decipiens), sedangkan areal playground didominasi dengan jenis tanaman buah seperti tanaman buni (Antidesma bunius L.), nangka (Artocarpus heterophyllus) dan belimbing wuluh (Averrhoa bilimbi).

b. Elemen hardscape

Elemen hardscape merupakan bagian dari elemen taman yang bersifat keras. Elemen hardscape di areal jogging track dan playground Puspem Badung meliputi bangku taman, lampu taman, jalan setapak, planter box, patung, kolam dan fasilitas permainan anak.

\subsection{Pengelolaan Taman}

\subsubsection{Sistem Pemeliharaan Taman}

Pelaksanaan pemeliharaan taman dilakukan secara mandiri dengan menerapkan sistem pemeliharaan unit yaitu sistem pemeliharaan yang didasarkan pada unit-unit taman yang ada dan sistem pemeliharaan khusus yaitu pemeliharaan yang dikerjakan berdasarkan keahlian tenaga kerja (Arifin dan Arifin, 2005). Berdasarkan observasi, pelaksanaan dilapangan dengan sistem pemeliharaan unit dikerjakan secara gotong royong oleh gardener disetiap unitnya. Sedangkan sistem pemeliharaan khusus dikerjakan oleh tenaga kerja ahli seperti kegiatan pemangkasan pohon, pemeliharaan hardscape dan penyulaman tanaman.

\subsubsection{Konsep Pemeliharaan Taman}

Bentuk pemeliharaan taman yang diterapkan adalah pemeliharaan ideal dan pemeliharaan fisik. Pelaksanaan pemeliharaan ideal dilakukan pada waktu tertentu yang meliputi kegiatan pergantian tanaman dan perbaikan hardscape taman, jika dilakukan penambahan dan pergantian tanaman maka harus mengacu pada konsep awal taman yaitu konsep taman yang bersih, hijau dan berbunga, sedangkan pemeliharaan fisik dilakukan untuk menunjang pemeliharaan ideal. Kegiatan secara rutin meliputi pembersihan areal taman, penyiraman, pengangkutan sampah, pendangiran dan penyiangan gulma, sementara kegiatan secara berkala meliputi pemangkasan tanaman, pemupukan, pengendalian hama dan penyakit.

\subsubsection{Tenaga Kerja}

Tenaga kerja yang bertugas di areal jogging track dan playground Puspem Badung terdapat dua orang pengawas lapangan dan tujuh belas orang gardener. Menurut perjanjian kerja seluruh pekerja bekerja maksimum tujuh jam kerja dimulai dari hari senin hingga hari sabtu. Gardener yang bertugas untuk kegiatan pemeliharaan secara rutin, jam kerja pukul 06.00-13.00 wita. Dalam penelitian ini mencakup dua wilayah kerja yaitu pada areal jogging track dan playground. Wilayah kerja dibagi menjadi enam unit dan semua pekerjaan pemeliharaan taman setiap arealnya diawasi oleh satu orang pengawas lapangan (Gambar 4).

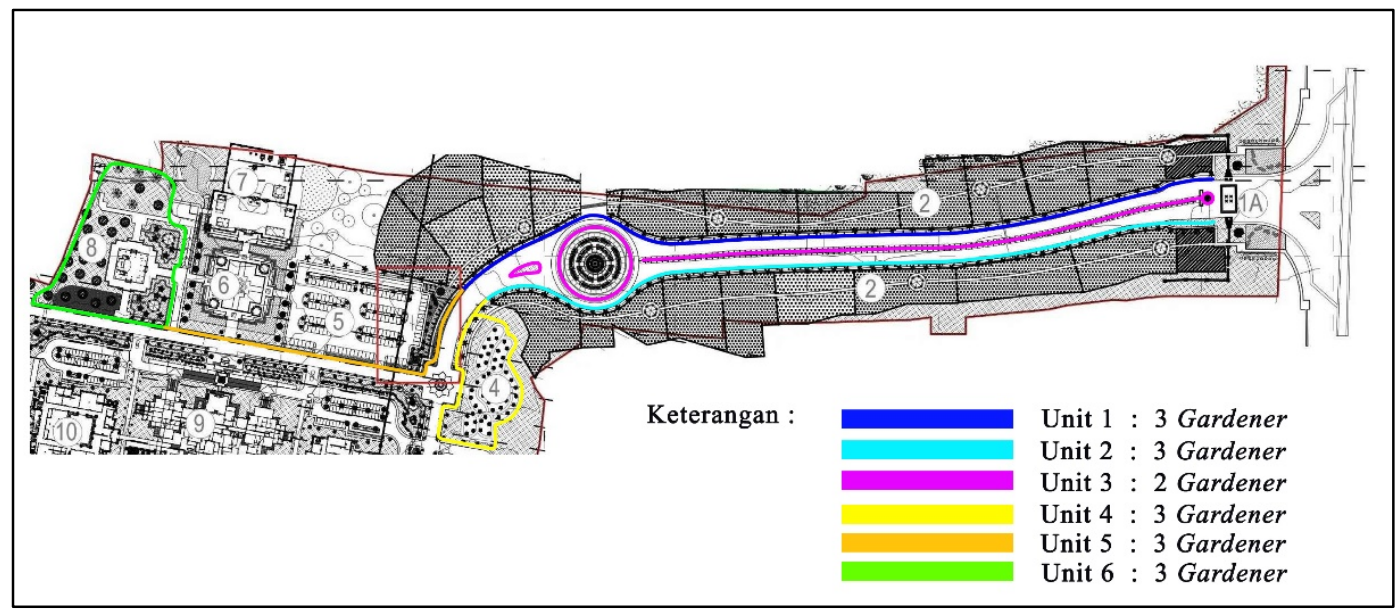

Gambar 3. Pembagian Unit Kerja

Penghasilan yang diterima setiap satu bulan oleh para pekerja yaitu sesuai dengan UMR Kabupaten Badung. Selain itu, tunjangan lainnya yang diterima adalah asuransi kesehatan dan jaminan keselamatan bekerja. Berdasarkan wawacara dengan gardener, terdapat keluhan yang disampaikan selama bekerja yaitu kurangnya penghargaan atau reward berupa pemberian bonus tambahan kepada pekerja yang rajin dan giat 
bekerja. Reward tersebut sangat diharapkan agar pimpinan lebih memperhatikan presetasi kerja dan pemberian diberikan secara adil. Tujuan diberikannya reward yaitu sebagai bentuk dedikasi kerja, agar mereka lebih bersemangat dan giat untuk melakukan pekerjaan di lapangan. Hal ini didukung penelitian Pranata et al., (2018), bahwa diberlakukannya sistem penghargaan dan sanksi bagi pekerja taman bertujuan untuk meningkatkan motivasi dan disiplin kerja.

\subsubsection{Pelaksanaan Pemeliharaan Taman}

a. Penyapuan

Kegiatan penyapuan dilakukan setiap hari yaitu pada pagi dan siang hari bertujuan untuk mejaga kebersihan taman. Alat yang digunakan terdiri dari sapu lidi dan pengki (Gambar $5 a$ ).

Arifin dan Arifin (2005) menyatakan, kegiatan penyapuan dapat dikatakan efektif dan efisien jika memiliki kapasitas kerja sebesar 800 m²/jam/orang. Kegiatan penyapuan pada bagian rumput dan perkerasan dikerjakan secara bersamaan oleh gardener dengan kapasitas kerja penyapuan sebesar 650 m²/jam/orang atau $81 \%$ yaitu lebih rendah $19 \%$ dari kapasitas kerja ideal. Berdasarkan pengamatan hal ini disebabkan, pertama banyaknya sampah daun dari tanaman jenis pohon yang berguguran setiap harinya. Kedua, terdapat beberapa gardener saat bekerja jika tidak diawasi oleh pengawas lapangan mereka akan bekerja tidak sesuai dengan waktu yang ditentukan. Ketiga, alat kerja yang digunakan yaitu sapu dan pengki bersifat tidak tahan lama dikarenakan intensitas penggunaan sehari - hari. Keempat, perbedaan kondisi lahan di setiap unit. Maka dari itu diperlukan evaluasi terhadap penggunaan alat kerja, penyetaraan jumlah pekerja sesuai dengan luas setiap unit dan tindakan tegas dari pengawas lapangan jika terjadi keterlambatan pekerjaan.

b. Penyiraman

Kegiatan penyiraman dilakukan setiap dua kali sehari dan tergantung kondisi cuaca. Alat yang digunakan saat penyiraman yaitu dengan menggunakan selang plastik 1 inci dan mobil tangki air (Gambar $5 b$ ).

Arifin dan Arifin (2005) menyatakan, kegiatan penyiraman dapat dikatakan efektif dan efisien jika memiliki kapasitas kerja sebesar $150 \mathrm{~m}^{2} / \mathrm{jam} /$ orang. Kegiatan penyiraman pada areal jogging track dan playground dominan menggunakan selang 1 inci $(2.54 \mathrm{~cm})$ dengan kapasitas kerja penyiraman sebesar 170 $\mathrm{m}^{2} /$ jam/orang atau $113 \%$ yaitu lebih besar $13 \%$ dari kapasitas kerja ideal. Hal ini disebabkan pelaksanaannya menggunakan selang ukuran 1 inci dan mengeluarkan debit air hamper 1 liter/2-3 detik, berbanding dengan standar kapasitas kerja Arifin dan Arifin (2005) yang menggunakan selang ukuran 3/4 inci.

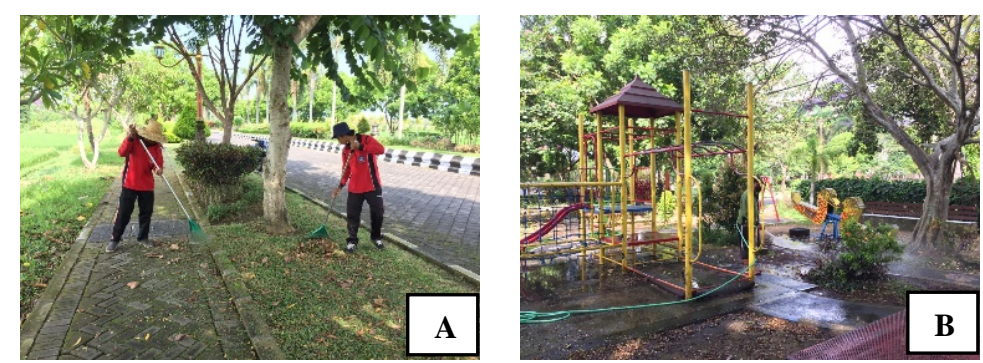

Gambar 4. Kegiatan (a) Penyapuan dan (b) Penyiraman

\section{c. Pemangkasan}

Kegiatan pemangkasan meliputi pemangkasan rumput yang dikerjakan secara intensif dan dilakukan dua sampai tiga kali sebulan tergantung kondisi cuaca dan intensitas pertumbuhan rumput. Alat yang digunakan adalah mesin pangkas gendong dan pangkas dorong (Gambar 6a). Arifin dan Arifin (2005) menyatakan, bahwa kegiatan pemangkasan rumput dapat dikatakan efektif dan efisien jika memiliki kapasitas kerja sebesar $250 \mathrm{~m} 2 /$ jam/orang dengan mesin gendong dan sebesar $500 \mathrm{~m} 2 / \mathrm{jam} /$ orang dengan mesin dorong. Berdasarkan perhitungan di lapangan kegiatan pemangkasan rumput menggunakan mesin gendong sebesar $300 \mathrm{~m} 2 /$ jam/orang atau 120\% dari kapasitas kerja ideal dan menggunakan mesing dorong sebesar 500 $\mathrm{m} 2 / j$ jam/orang atau $100 \%$ dari kapasitas kerja ideal. Hal ini disebabkan karena penggunaan dan pemilihan jenis mesin ditentukan oleh luas area yang akan dipangkas, jika lahan yang luas pekerja akan menggunakan pangkas dorong, sedangkan lahan yang sempit pekerja menggunakan pangkas gendong. 
Kegiatan pemangkasan semak dan perdu dilakukan secara fleksibel atau sesuai kebutuhan. Alat yang digunakan adalah sabit dan gunting pangkas (Gambar 6b). Sampah hasil kegiatan pemangkasan akan dikumpulkan dan diangkut dengan mobil sampah. Sebagaian sisa sampah daun akan dikirimkan ke pabrik pengolahaan pembuatan pupuk kompos. Sementara kegiatan pemangkasan pohon dilakukan secara tidak rutin dikarenakan kemampuan pekerja yang kurang memadai. Pertumbuhan pohon yang merusak perkerasan dan ranting-ranting pohon yang berjatuhan di areal taman dapat mengganggu keselamatan dari penjunjung. Oleh sebab itu perlu diajukan pergantian pohon kepada pimpinan dengan memperhatikan kondisi eksisting, pemilihan jenis pohon, teknik penanaman, alat kerja dan jumlah pekerja yang digunakan. Selanjutnya kegiatan pemangkasan pohon sebaiknya dilakukan secara berkala minimal tiga bulan sekali bertujuan untuk menjaga kesehatan pohon dan keselamatan pengunjung taman.
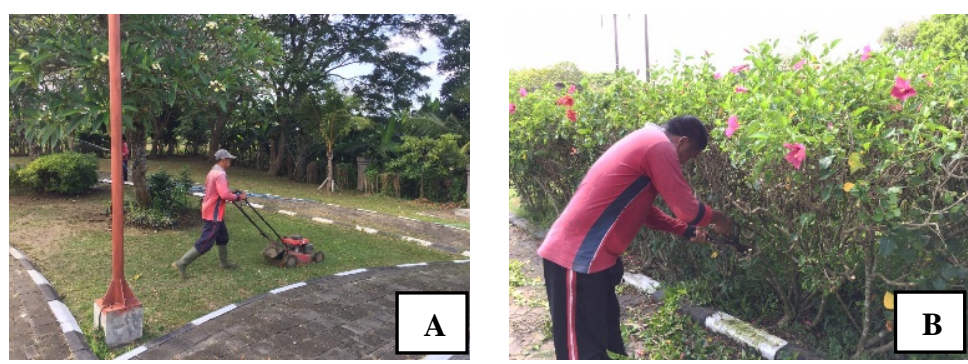

Gambar 5. Kegiatan Pemangkasan (a) Rumput dan (b) Semak dan Perdu

\section{d. Pemupukan}

Kegiatan pemupukan dilakukan setiap tiga bulan sekali. Pupuk yang digunakan yaitu pupuk organik meliputi pupuk kompos dan pupuk kandang, sementara pupuk anorganik meliputi pupuk urea dan pupuk NPK.

Arifin dan Arifin (2005) menyatakan, kegiatan pemupukan dapat dikatakan efektif dan efisien jika

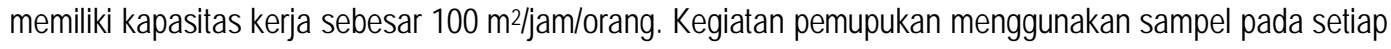
unit sesuai dengan penggunaan jenis pupuk pada tanaman semak dan penutup tanah, yang memperoleh ratarata keseluruhan sebesar $85 \mathrm{~m} 2 /$ jam/orang atau $85 \%$ yaitu lebih rendah 15\% dari kapasitas kerja ideal. Hal ini disebabkan karena gardener tidak terburu-buru saat memberikan pupuk pada tanaman semak dan penutup tanah, gardener sangat berhati-hati agar tidak terjadi kesalahan penakaran pupuk. Walaupun pengaplikasian di lapangan lebih rendah dari kapasitas kerja ideal, akan tetapi gardener sudah melakukan kegiatan pemupukan secara baik. Menurut Oktaviarni (2008), kegiatan pemupukan sebaiknya dilakukan pada musim hujan dan apabila pemupukan tanpa diikuti dengan penyiraman maka akan menyebabkan kerusakan tanaman

e. Pendangiran dan Penyiangan Gulma

Kegiatan pendangiran dan penyiangan gulma dilakukan secara bersamaan setiap harinya. Pendangiran merupakan kegiatan penggemburan tanah disekitar area titik tanam tanaman (Gambar 7a), sementara penyiangan bertujuan untuk menghilangkan tanaman liar di sekitar tanaman utama yang dilakukan secara manual yaitu dicabut menggunakan tangan maupun alat seperti kored (Gambar 7b).

Arifin dan Arifin (2005) menyatakan, kegiatan pendangiran dan penyiangan gulma dapat dikatakan

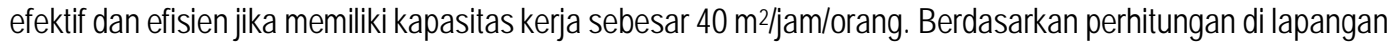
kegiatan pendangiran dan penyiangan gulma sebesar 45 m²/jam/orang atau $113 \%$ yaitu lebih besar 13\% dari kapasitas kerja ideal. Hal ini disebabkan karena gardener melakukannya setiap hari sehingga sudah memahami pekerjaan yang dilakukan. 


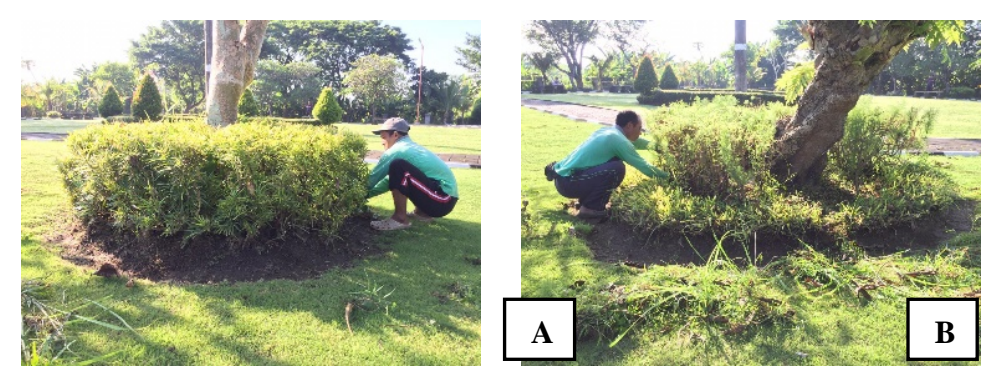

Gambar 6. Kegiatan (a) Pendangiran dan (b) Penyiangan Gulma

\section{f. Pengendalian Hama dan Penyakit}

Kegiatan pengendalian hama dan penyakit dilakukan secara insidentil bila sudah terjadi serangan hama atau mulai terkena gejala penyakit. Metode pencegahan yang dilakukan yaitu menggunakan metode kimiawi dengan pestisida. Metode lain yang dapat dilakukan untuk pencegahan yaitu dengan cara membuang atau mematahkan bagian tanaman yang terserang (Ruba et al., 2015). Alat yang digunakan yaitu sprayer gendong. Insektisida yang digunakan adalah Curacron, yang merupakan insektisida multifungsi dan dapat digunakan untuk mengendalikan hampir semua jenis hama serangga. Kemudian fungisida yang digunakan adalah FX, yang merupakan fungisida dari bahan-bahan alami tanpa kandungan bahan kimia, bertujuan untuk meminimalisir kemampuan spora jamur untuk berkembang dan menyebar pada tanaman.

g. Pemeliharaan Hardscape Taman

Pemeliharaan hardscape yang berhubungan dengan kelistrikan, seperti lampu taman, kolam serta perawatan wahana bermain yang rusak dilakukan oleh tenaga ahli pada bidangnya. Gardener bertugas melakukan pembersihan untuk mejaga kualitas ornamen taman seperti penyikatan patung, kolam, pot / planter box dari lumut dan pembersihan tumbuhan liar seperti gulma dan daun-daun kering yang berjatuhan. Alat yang digunakan yaitu sikat, selang dan ember.

h. Penyulaman Tanaman

Kegiatan penyulaman tanaman dilakukan oleh pihak kedua yaitu pemborong taman yang sudah berkerjasama dengan Sub. Bagian Perawatan Puspem Badung. Pergantian tanaman hanya dilakukan pada jenis tanaman penutup tanah yang bersifat tahunan seperti tanaman sutra bombay (Portulaca sp.) dan seruni rambat (Widelia trilobata), bertujuan agar taman tetap indah melalui perpaduan warna bunga tanaman. Menurut Arifin dan Arifin (2005), jenis tanaman setahun akan mati setelah melampaui masa reproduktif berbunga atau berbuah, kehadiran tanaman ini sangat dibutuhkan untuk menghindari kesan kemonotonan warna, bentuk dan ukuran tanaman dalam suatu taman.

\subsubsection{Alat dan Bahan Pemeliharaan}

Peralatan pemeliharaan taman di areal jogging track dan playground Puspem Badung dinilai masih baik dan efektif menurut pengelola taman. Menurut Sinaga et al., (2019), masa efektif barang dapat diketahui melalui pengalaman atau studi pustaka pemeliharaan taman. Masa efektif alat kerja pemeliharaan taman Puspem Badung dapat dilihat pada Tabel 2. sebagai berikut.

Tabel 2. Masa Efektif Alat Kerja Pemeliharaan Taman Puspem Badung

\begin{tabular}{llcc}
\hline No. & \multicolumn{1}{c}{ Alat Kerja } & \multicolumn{2}{c}{ Masa Efektif } \\
\cline { 3 - 4 } & & 3 bulan & (b) \\
\hline 1. & Sapu lidi & 3 bulan & 1 bulan \\
2. & Sapu daun & 3 bulan & 6 bulan \\
3. & Pengki & 1 tahun & - \\
4. & Selang Air & 1 tahun & 6 bulan \\
5. & Gunting Pangkas & 1 tahun & 6 bulan \\
6. & Cangkul & 6 bulan & 6 bulan \\
7. & Sabit & 6 bulan & 6 bulan \\
8. & Kored & 1 tahun & 3 tahun \\
9. & Handsprayer & 3 tahun & - \\
10. & Knapsack-sprayer & &
\end{tabular}




\begin{tabular}{lllc}
\hline No. & \multicolumn{1}{c}{ Alat Kerja } & \multicolumn{2}{c}{ Masa Efektif } \\
\cline { 3 - 4 } & & (a) & (b) \\
\hline 11. & Mesin pemotong rumput gendong & 3 tahun & 3 tahun \\
12. & Mesin pemotong rumput dorong & 1 tahun & 3 tahun \\
13. & Gergaji manual & 1 tahun & - \\
14. & Seragam operator pemeliharaan taman & 6 bulan \\
\hline
\end{tabular}

Keterangan : (a) Wawancara di lapangan

(b) Sumber: Wulandari (1992) dalam Arifin dan Arifin (2005)

Peralatan pemeliharaan harus diketahui masa efektifnya untuk mengetahui biaya penyusutan barang dalam rencana anggaran pemeliharaan taman (Sinaga et al., 2019). Perawatan alat kerja merupakan tanggung jawab dari para pekerja. Perawatan alat berat seperti mesin pemangkas akan dilakukan oleh tenaga ahli yang bertujuan untuk memperpanjang umur mesin dan menjaga kualitas mesin agar tetap awet. Ketahanan alat kerja pemeliharaan taman didasarkan pada kapasitas atau lama penggunaanya. Bahan yang digunakan untuk kegiatan pemeliharaan meliputi air penyiraman yang berasal dari air sumur bor dan air irigasi subak. Pupuk meliputi pupuk organik dan anorganik. Pestisida dengan jenis insektisida dan fungisida, serta bahan bakar untuk mesin pemangkas rumput.

\subsubsection{Kapasitas Kerja Pemeliharaan Taman}

Kapasitas kerja pemeliharaan taman di areal jogging track dan playground Puspem Badung diperoleh berdasarkan hasil rata-rata penghitungan setiap unit, yang kemudian dibandingkan dengan kapasitas kerja berdasarkan teori ahli Arifin dan Arifin (2005). Kapasitas kerja pemeliharaan taman dapat dilihat pada Tabel 3. Berikut.

Tabel 3. Kapasitas Tenaga Kerja Pemeliharaan Taman

\begin{tabular}{|c|c|c|c|c|c|c|c|c|c|c|}
\hline \multirow[t]{2}{*}{ No. } & \multirow{2}{*}{$\begin{array}{l}\text { Jenis pekerjaan } \\
\text { pemeliharaan }\end{array}$} & \multicolumn{6}{|c|}{$\begin{array}{c}\text { Kapasitas kerja per unit } \\
\left(\mathrm{m}^{2} / \text { jam/orang }\right)\end{array}$} & \multirow{2}{*}{$\begin{array}{l}\text { Rata - } \\
\text { Rata }\end{array}$} & \multirow{2}{*}{$\begin{array}{l}\text { Standar } \\
\text { Ideal }\end{array}$} & \multirow[t]{2}{*}{$(\%)$} \\
\hline & & 1 & 2 & 3 & 4 & 5 & 6 & & & \\
\hline 1. & $\begin{array}{l}\text { Penyapuan dengan } \\
\text { sapu lidi }\end{array}$ & 650 & 630 & 670 & 635 & 685 & 630 & $650 \mathrm{~m}^{2}$ & $800 \mathrm{~m}^{2}$ & $81 \%$ \\
\hline 2. & $\begin{array}{l}\text { Penyiraman dengan } \\
\text { selang plastik } 1 \text { inci }\end{array}$ & - & - & - & 175 & 160 & 175 & $170 \mathrm{~m}^{2}$ & $150 \mathrm{~m}^{2}$ & $113 \%$ \\
\hline 3. & $\begin{array}{l}\text { Pemangkasan } \\
\text { rumput dengan } \\
\text { mesin gendong }\end{array}$ & 320 & 320 & 350 & 285 & 275 & 250 & $300 \mathrm{~m}^{2}$ & $250 \mathrm{~m}^{2}$ & $120 \%$ \\
\hline 4. & $\begin{array}{l}\text { Pemangkasan } \\
\text { rumput dengan } \\
\text { mesin dorong }\end{array}$ & - & - & - & 525 & - & 475 & $500 \mathrm{~m}^{2}$ & $500 \mathrm{~m}^{2}$ & $100 \%$ \\
\hline 5. & $\begin{array}{l}\text { Pendangiran dan } \\
\text { penyiangan gulma } \\
\text { dengan kored }\end{array}$ & 47 & 45 & 43 & 45 & 42 & 48 & $45 \mathrm{~m}^{2}$ & $40 \mathrm{~m}^{2}$ & $113 \%$ \\
\hline 6. & $\begin{array}{l}\text { Pemupukan pada } \\
\text { tanaman semak dan } \\
\text { penutup tanah }\end{array}$ & 84 & 80 & 87 & 84 & 85 & 90 & $85 m^{2}$ & $100 \mathrm{~m}^{2}$ & $85 \%$ \\
\hline
\end{tabular}

Hasil perbandingan standar kapasitas kerja ideal di areal jogging track dan playground Puspem Badung, terdapat dua jenis pekerjaan yang kurang dari standar yaitu kegiatan penyapuan dan pemupukan (di bawah 100\%) kemudian jenis pekerjaan yang melebihi standar yaitu kegiatan penyiraman, pemangkasan rumput, pendangiran dan penyiangan gulma (di atas 100\%, dapat dinyatakan sudah berjalan efektif dan efisien). Permasalahan terdapatnya kegiatan pemeliharaan yang kurang dari standar disebabkan karena para pekerja menunda pekerjaan, beristirahat pada jam kerja, kerusakan alat kerja, teknik pemeliharaan yang digunakan oleh setiap individu gardener berbeda-beda dan perbedaan kondisi lahan di setiap unit. Permasalahan tersebut dapat diatasi dengan adanya standar operasional prosedur tentang pelaksanaan 
pemeliharaan taman, kemudian meningkatkan pengawasan di lapangan, melakukan perawatan alat kerja secara rutin, perlu adanya penyetaraan alat kerja dan perlu diadakannya pelatihan pemeliharaan taman kepada para pekerja untuk memahami teknik dan keterampilan di lapangan. Selain itu terdapat pula faktor tingkat keterampilan dan pengalaman kerja yang lebih lama memungkinkan terdapat kapasitas kerja pemelihataan yang lebih tinggi sehingga melebihi standar.

\subsection{Persepsi Pengunjung}

Hasil dari tabulasi data kuesioner diperoleh identitas dan persepsi responden mengenai kondisi fisik taman. Identitas responden dalam penelitian ini terderi dari jenis kelamin, usia, waktu kunjungan, pekerjaan dan aktivitas berkunjung. Adapun identitas responden dapat dilihat pada Gambar 7 berikut.

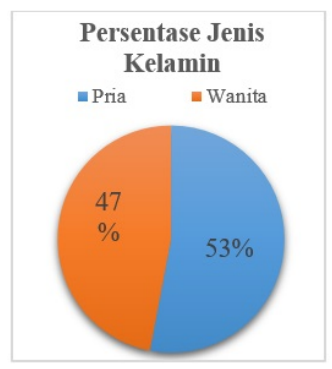

(a). Jenis Kelamin

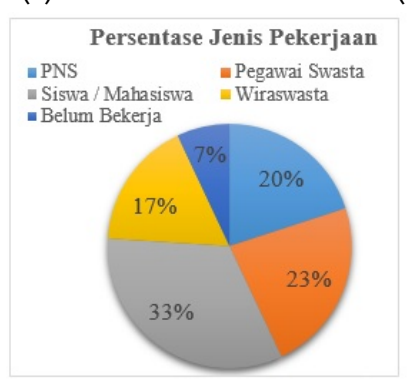

(d). Pekerjaan

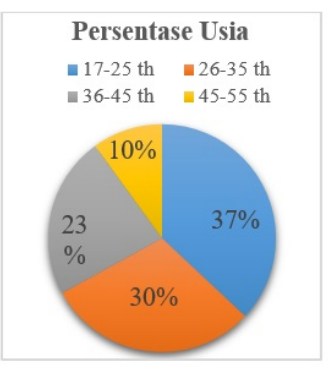

(b). Usia

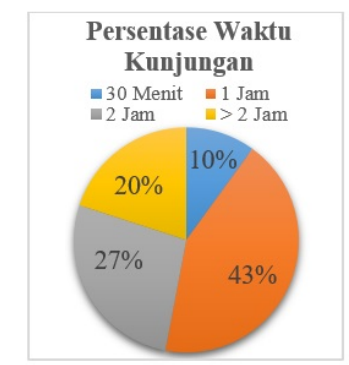

(c). Waktu Kunjungan

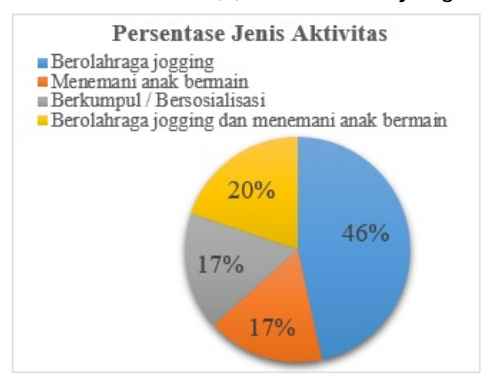

(e). Aktivitas Berkunjung

Gambar 7. Identitas Responden

Pemeliharaan taman di areal jogging track dan playground Puspem Badung bertujuan untuk menjaga kebersihan, keamanan dan keindahan pada taman, agar dapat memberikan rasa nyaman kepada para pengunjung saat melakukan aktivitas berolahraga dan berekreasi. Persepsi responden yang diamati dalam penelitian ini terkait dengan kondisi fisik taman di areal jogging track dan playground Puspem Badung meliputi kebersihan taman, pedestrian, bangku taman, planter box, keamanan dan keindahan taman. Persentase indikator penilaian dapat dilihat pada Gambar 8 berikut.

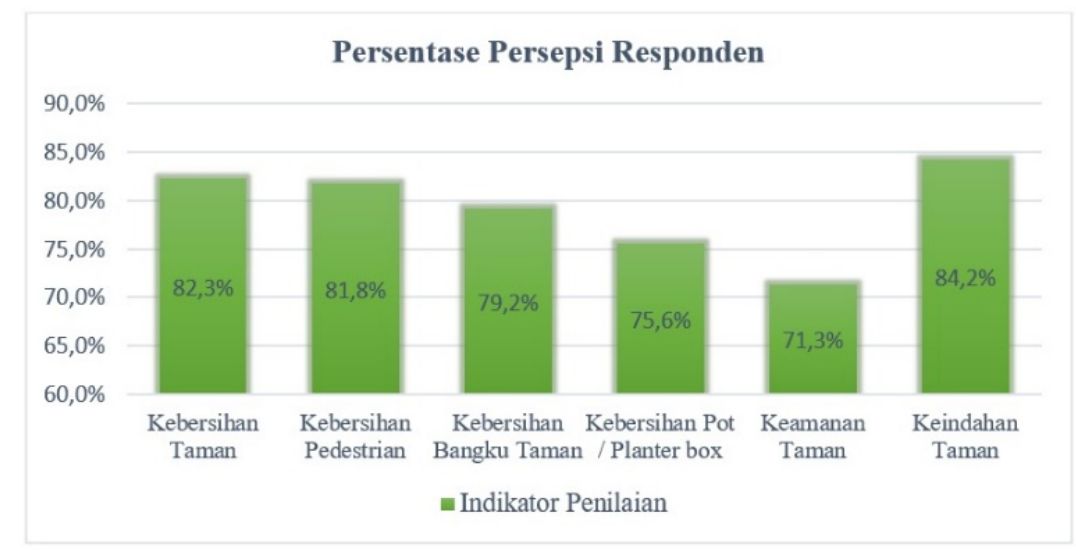

Gambar 8. Persentase Persepsi Responden 
Hasil persepsi pengunjung terhadap kondisi fisik taman pada areal jogging track dan playground Puspem Badung mengenai kebersihan taman, kebersihan pedestrian dan keindahan taman mendapatkan persepsi sangat baik, sedangkan untuk kebersihan bangku taman, kebersihan pot/planter box dan keamanan taman mendapatkan persepsi baik.

\section{Simpulan dan Saran \\ 4.1 Simpulan}

Berdasarkan hasil penelitian dapat ditarik simpulan sebagai berikut:

Sistem pemeliharaan yang diterapkan yaitu sistem pemeliharaan unit dan khusus. Hasil evaluasi pelaksanaan pemeliharaan taman berdasarkan penghitungan kapasitas kerja ideal terdapat dua pekerjaan yang kurang dari standar yaitu kegiatan penyapuan dan pemupukan, sementara pekerjaan yang melebihi standar yaitu kegiatan penyiraman, pemangkasan, pendangiran dan penyiangan gulma. Persepsi pengunjung terhadap kondisi fisik taman dinilai sudah baik, dilihat dari indikator kebersihan taman berada dalam kategori sangat baik, kebersihan pedestrian berada dalam kategori sangat baik, kebersihan bangku taman berada dalam kategori baik, kebersihan planter box berada dalam kategori baik, keamanan taman berada dalam kategori baik, dan keindahan taman berada dalam kategori sangat baik. Hal ini menunjukkan bahwa pihak pengelola taman telah melakukan pemeliharaan secara baik didukung dengan pelaksanaan pemeliharaan yang intensif dan kapasitas tenaga kerja yang dimiliki.

\subsection{Saran}

Pelaksanaan pemeliharaan sudah dapat dikatakan efektif dan efisien namun pemeliharaannya tidak berjalan secara ideal. Oleh sebab itu saran dalam penelitian ini yaitu perlu standar operasional prosedur pelaksanaan pemeliharaan taman secara tertulis dan diajukannya kegiatan pemangkasan pohon minimal tiga bulan sekali.

\section{Daftar Pustaka}

Arifin, H. S., \& Arifin, N. H. S. 2005. Pemeliharaan Taman (Edisi Revisi). Penebar Swadaya, Jakarta.

Oktaviarni, S. I. 2008. Pengelolaan Pemeliharaan Lanskap di Kawasan Permukiman Sentul City, Bogor, Jawa Barat. Skripsi (tidak dipublikasikan) Program Studi Arsitektur Lanskap, Fakultas Pertanian, Institut Pertanian Bogor.

Pranata, I. N. D., Sudarsana, A. A. G. D., \& Mayadewi, N. N. A. 2018. Efisiensi pemeliharaan taman: studi kasus di hotel the Oberoi, Bali. Jurnal Arsitektur Lansekap, 4(1):51-58.

Ruba, V. C. F., Utami, N. W. F., \& Adnyana, G. M. 2015. Pemeliharaan Fisik Taman Nostalgia Kota Kupang Provinsi Nusa Tenggara Timur. Jurnal Arsitektur Lansekap, 1(2):58-70.

Sinaga, S., Semarajaya, C. G. A., \& Mayadewi, N. N. A. 2019. Rencana pemeliharaan taman Museum Arma Ubud. Jurnal Arsitektur Lanskap, 5(2):196-205.

Strenloff, R. E., \& Warren, R. 1984. Park and Recreation Maintenance Management. In John Wiley and Sons, Canada.

Sugiyono. 2017. Metodologi penelitian kuantitatif kualitatif dan R\&D. In Alpabeta, Bandung. 